\title{
Author Correction: Tumor cells suppress radiation-induced immunity by hijacking caspase 9 signaling
}

Chuanhui Han, Zhida Liu, Yunjia Zhang, Aijun Shen, Chunbo Dong, Anli Zhang (1D, Casey Moore (D), Zhenhua Ren (1), Changzheng Lu, Xuezhi Cao, Chun-Li Zhang, Jian Qiao (1) and Yang-Xin Fu (D)

Correction to: Nature Immunology https://doi.org/10.1038/s41590-020-0641-5, published online 30 March 2020.

In the version of this article initially published, in the Methods section "Tumor growth and treatments," a description of the vehicle used as the control treatment (no emricasan) was omitted. For the emricasan dissolved in $2 \%$ alginate in PBS treatment, the corresponding vehicle control was $2 \%$ alginate in PBS without emricasan. For the emricasan dissolved in PBS treatment, the corresponding vehicle control was PBS without emricasan. The error has been corrected in the HTML and PDF versions of the article.

Published online: 16 September 2020

https://doi.org/10.1038/s41590-020-00805-0

(C) The Author(s), under exclusive licence to Springer Nature America, Inc. 2020

\section{Publisher Correction: SARS-CoV-2 infection of human ACE2-transgenic mice causes severe lung inflammation and impaired function}

Emma S. Winkler, Adam L. Bailey, Natasha M. Kafai, Sharmila Nair, Broc T. McCune, Jinsheng Yu DD, Julie M. Fox (D), Rita E. Chen, James T. Earnest, Shamus P. Keeler (D), Jon H. Ritter, Liang-I Kang, Sarah Dort, Annette Robichaud, Richard Head, Michael J. Holtzman (D) and Michael S. Diamond (D)

Correction to: Nature Immunology https://doi.org/10.1038/s41590-020-0778-2, published online 24 August 2020.

In the version of this article initially published online, in Fig. $4 \mathrm{~b}$, the cells on the far left of the graph were incorrectly identified as CD44 ${ }^{+}$ cells. The correct label is CD45+ cells. The error has been corrected in the print, PDF and HTML versions of the article.

Published online: 2 September 2020

https://doi.org/10.1038/s41590-020-0794-2

(C) The Author(s), under exclusive licence to Springer Nature America, Inc. 2020

\section{Publisher Correction: Captain GBP1: inflammasomes assemble, pyroptotic endgame}

Shouya Feng and Si Ming Man (D)

Correction to: Nature Immunology https://doi.org/10.1038/s41590-020-0727-0, published online 22 July 2020.

In the version of this article initially published, reference 12 was cited incorrectly. The correct reference is: Kutsch, M. et al. EMBO J. 39, e104926 (2020). The error has been corrected in the HTML and PDF versions of the article.

Published online: 10 September 2020

https://doi.org/10.1038/s41590-020-00804-1

(C) The Author(s), under exclusive licence to Springer Nature America, Inc. 2020 